\title{
Right dorsal colitis in the horse: minireview and reports on three cases in Ireland
}

\author{
Noreen Galvin, ${ }^{1}$ Hugh Dillon ${ }^{2}$ and Frank McGovern ${ }^{2}$ \\ ${ }^{1}$ Bohergoy, Maddenstown, The Curragh, Co Kildare, Ireland \\ 2 Troytown Equine Hospital, Green Road, Kildare Town, Co Kildare, Ireland
}

Right dorsal colitis (RDC) is an ulcerative inflammatory bowel disorder of the horse that has been associated with the administration of non-steroidal anti-inflammatory drugs (NSAIDs), particularly in horses treated when dehydrated or toxaemic. The acute form of RDC may result in profuse diarrhoea, severe colic, dehydration, endotoxic shock and even death; the chronic form may be manifest by mild to moderate intermittent colic, ventral oedema and weight loss with or without diarrhoea. The most consistent laboratory findings are anaemia, hypoproteinaemia, hypoalbuminaemia and hypocalcaemia. Medical management of RDC requires avoidance of NSAIDs, of stressful experiences and of large-volume diets. Specific medications such as sucralfate and metronidazole have been used to treat RDC in the horse. The use of dietary additions such as psyllium and corn oil has been mentioned in the literature.

RDC has not been reported previously in Ireland or Britain; here we report that the condition was diagnosed in three horses in Ireland on the bases of a history of phenylbutazone therapy, clinical signs, clinical pathology and ultrasonography. In two of the three horses the diagnosis was confirmed by direct inspection of the affected colon at celiotomy.

Irish Veterinary Journal

Volume 57: 467 - 473, 2004

\section{Introduction}

Right dorsal colitis is a specific type of protein-losing, ulcerative inflammatory bowel disorder of the horse that has been associated with the administration of non-steroidal antiinflammatory drugs (NSAIDs), most commonly phenylbutazone (Karcher et al., 1990). Although the condition is relatively common in the USA, it has not been reported in Ireland or Britain, despite many horses receiving phenylbutazone therapy. In this paper we provide a minireview of the literature on RDC and we report the diagnosis of the condition in three horses in Ireland.

\section{Corresponding author:}

Noreen Galvin

Bohergoy,

Maddenstown,

The Curragh,

Co Kildare, Ireland

Tel: 087267 3145; E-mail: galvinnoreen@eircom.net.

\author{
Key words \\ Horse, \\ Right dorsal colitis, \\ Phenylbutazone, \\ Diarrhoea, \\ Colic, \\ Loss of weight.
}

\section{Minireview of the literature \\ Pathogenesis}

There is evidence that dehydration, enterotoxaemia or preexisting lesions of the colon increase the risk of RDC amongst horses being treated with NSAIDs such as phenylbutazone or flunixin meglumine. NSAIDs can cause ulceration throughout the entire gastrointestinal tract of horses (MacAllister, 1983; MacKay et al., 1983; Collins and Tyler, 1984). The exact reason for the localization of ulceration in the right dorsal colon has not been elucidated; however, one hypothesis is that phenylbutazone is bound extensively to roughage and is released after fermentation in the large colon (Mathio et al., 1986). There is prolonged contact time between the drug and the right dorsal colon due to the slow transit time and the narrowing of the lumen at the junction of the right dorsal colon and the transverse colon (Cohen, 2002).

NSAIDs inhibit the cyclooxygenase (COX) enzyme, of which there are two known isoforms: COX-1 and COX-2 (Griswold and Adams, 1996). COX-1 mediates prostaglandin $\mathrm{E}_{2}$ cytoprotection in the gastrointestinal tract; COX-2 is the isoform 
that is responsible for the production of the prostaglandins associated with inflammation. Drugs such as phenylbutazone, which cause proportionately more inhibition of COX-1 than of COX-2, may cause a reduction in cytoprotective effects mediated by prostaglandin $\mathrm{E}_{2}$, resulting in hypoxic or ischaemic damage to the mucosa (Griswold and Adams, 1996).

The dose of phenylbutazone required to induce ulcerative colitis was initially thought to be greater than $10 \mathrm{mg} / \mathrm{kg}$ bwt s.i.d. for longer than seven to ten days (Meschter et al., 1990; MacAllister, 1983). However, in one study, RDC was induced in two horses by administering $6 \mathrm{mg} / \mathrm{kg}$ bwt phenylbutazone s.i.d. for five days while water intake was restricted to half maintenance requirements (Karcher et al., 1990).

The variable occurrence of the toxic side effects of phenylbutazone may be attributed to individual variation (i.e., age, breed, health status, hydration, diet, stress levels and duration of treatment). There appears to be a higher incidence in young horses and ponies, perhaps because young horses that are in work are more likely to be prescribed NSAIDs for treatment of musculoskeletal injuries (Cohen, 2002).

\section{Clinical aspects}

Clinical signs of acute RDC may include profuse diarrhoea, severe colic, dehydration, endotoxic shock and death. The chronic form may be manifested by mild to moderate intermittent colic, ventral oedema, weight loss with or without diarrhoea, the duration of which can vary from weeks to several months (Karcher et al., 1990; Simmons et al., 1990; Cohen et al., 1995a, b; Bueno et al., 2000; Cohen, 2002). The most consistent clinicopathological features include anaemia, hypoproteinaemia, hypoalbuminaemia and hypocalcaemia (Karcher et al., 1990; Cohen et al., 1995a, b), all probably due to losses through the damaged mucosa. Anaemia is usually mild, and the PCV rarely falls below $0.25 \mathrm{~L} / \mathrm{L}$ (Cohen et al., 1995a, b; Bueno et al., 2000; Cohen, 2002).

\section{Treatment}

Initial reports described RDC as a condition that needs surgical intervention; however, such surgical treatments were not successful (Karcher et al., 1990; Simmons et al., 1990). While definitive diagnosis requires exploratory laparotomy, this is unlikely to be the best therapeutic approach. Medical management is likely to provide a more satisfactory outcome if an accurate and early diagnosis can be made on the bases of history, clinical signs and clinical pathology, and if the owner can be persuaded to comply with the therapeutic and dietary constraints that must be observed. Medical management is based upon four main principles: avoid further use of NSAIDs, avoid stressful situations, modify the diet, and use specific medication.

Avoid further use of non-steroidal anti-inflammatory drugs

If the use of a non-steroidal anti-inflammatory drug is unavoidable, use less ulcerogenic drugs, such as ketoprofen, which are targeted more to inhibition of COX-2 than to inhibition of COX-1 (MacAllister et al., 1993).

\section{Avoid stressful situations}

Decreasing or discontinuing work regimes is important in the recovery phase of affected horses (Cohen, 2002). It is desirable to avoid any situations that may cause stress (such as changes in management regimes) or may precipitate dehydration (as in long distance transportation).

\section{Modify the diet}

Large-volume fibre sources should be eliminated to reduce the mechanical and physical load on the compromised colon, in order to favour mucosal healing (Cohen et al., 1995a; Cohen, 2002). A low bulk diet, consisting of a pelleted feed and small quantities of grass, should be provided in several small feeds during the day. Generally, a period of three to six months should be allowed for the colon to heal prior to reintroduction of bulk feed.

The use of psyllium mucilloid, a soluble dietary fibre, may be useful. When fed intermittently, it acts as a laxative. When fed continuously, it can result in the production of short-chain fatty acids, which may promote healing and repair of the colonic mucosa (Argenzio, 1994). The recommended dose is $100 \mathrm{~g}$ once daily for three to six months. However, control studies on psyllium mucilloid in equine species are lacking.

The addition of oils to the diet of horses with RDC has been proposed as beneficial (Bueno et al., 2000; Cohen, 2002). The addition of corn oil, 100 to $200 \mathrm{ml}$ daily, also has the advantage of introducing low-bulk calories to the patient's diet (Cohen et al., 1995a). Ensure plentiful water supply at all times to avoid dehydration.

\section{Use of specific medication}

$\mathrm{PGE}_{2}$ has been shown to prevent ulceration in the gastrointestinal tract of ponies (Collins and Tyler, 1985). Misoprostal is a synthetic analogue of $\mathrm{PGE}_{1}$. However, side effects (which may include abdominal discomfort) and cost are likely to limit its use in the horse. Other anti-ulcer medications

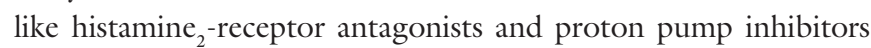
are unlikely to be effective in the treatment of RDC as their function is to decrease gastric acidity (Cohen et al., 1995b). They may have a role in treating concurrent gastric ulceration.

It has been suggested that sucralfate may be beneficial at $22 \mathrm{mg} / \mathrm{kg}$ bwt p.o. t.i.d. (MacAllister and Taylor-MacAllister, 1994). Administration can be relatively inexpensive and it has been used in cases of RDC (Cohen, 1995b).

Metronidazole and sulphasalazine have been used in human patients to deal with NSAID-induced enteropathies. The effects of sulphasalazine in the horse have not been evaluated. Metronidazole has been used in the treatment of RDC (Cohen, 2002). It should be added to the therapeutic regime if secondary anaerobic infection is suspected. Recently, glutamine has been 
TABLE 1: History and signalment of the three horses diagnosed with right dorsal colitis

\begin{tabular}{|c|c|c|c|}
\hline Horse & 1 & 2 & 3 \\
\hline Age (years) & 2 & 5 & 10 \\
\hline Gender & Colt & Gelding & Mare \\
\hline Breed & Thoroughbred & half breed & half breed \\
\hline $\begin{array}{l}\text { Clinical signs reported } \\
\text { by owner prior to admission }\end{array}$ & $\begin{array}{l}\text { Weight loss, } \\
\text { intermittent colic, } \\
\text { diarrhoea. }\end{array}$ & $\begin{array}{l}\text { Moderate bout } \\
\text { of colic. }\end{array}$ & $\begin{array}{l}\text { Weight loss, } \\
\text { intermittent colic } \\
\text { and diarrhoea. }\end{array}$ \\
\hline Duration of signs before admission (days) & 30 & 1 & 180 \\
\hline Duration of administration of phenylbutazone (days) & 7 & 14 & 20 \\
\hline $\begin{array}{l}\text { Estimated dose of phenylbutazone } \\
\text { administered (per os) }\end{array}$ & $\begin{array}{l}5 \mathrm{mg} / \mathrm{kg} / \text { bwt b.i.d. } \\
\text { for two day and } 2.5 \\
\mathrm{mg} / \mathrm{kg} / \text { bwt. b.i.d. for } \\
\text { five days }\end{array}$ & $\begin{array}{l}4 \mathrm{mg} / \mathrm{kg} / \text { bwt b.i.d. } \\
\text { for two days } \\
\text { and } 2 \mathrm{mg} / \mathrm{kg} / \text { bwt } \\
\text { b.i.d. for twelve days }\end{array}$ & $\begin{array}{l}\text { precise data } \\
\text { not available }\end{array}$ \\
\hline
\end{tabular}

\begin{tabular}{|c|c|c|c|c|}
\hline \multicolumn{5}{|c|}{ TABLE 2: Clinical examination of the three horses on admission } \\
\hline Horse & 1 & 2 & \multicolumn{2}{|c|}{3} \\
\hline Demeanour & Comfortable & $\begin{array}{c}\text { Exhibiting signs } \\
\text { of abdominal discomfort }\end{array}$ & \multicolumn{2}{|c|}{ Comfortable } \\
\hline Heart rate (per minute) & 36 & 50 & \multicolumn{2}{|c|}{40} \\
\hline Respiratory rate (per minute) & 12 & 18 & \multicolumn{2}{|c|}{16} \\
\hline Temperature ${ }^{\circ} \mathrm{C}$ & 37.6 & 38 & \multicolumn{2}{|c|}{37.9} \\
\hline Mucous membranes & Pale, $\mathrm{CRT}<2 \mathrm{sec}$ & \multirow{2}{*}{$\begin{array}{l}\text { Pale, CRT }<2 \mathrm{sec} \\
\text { Normal motility }\end{array}$} & \multicolumn{2}{|c|}{ Pale, $\mathrm{CRT}<2 \mathrm{sec}$} \\
\hline \multirow[t]{4}{*}{ Abdominal auscultation } & Reduced motility & & Norm & notility \\
\hline & $\mathrm{L} \quad \mathrm{R}$ & $\mathrm{L} \quad \mathrm{R}$ & $\mathrm{L}$ & $\mathrm{R}$ \\
\hline & + & ++ & ++ & ++ \\
\hline & $+\quad-$ & $++\quad++$ & ++ & ++ \\
\hline Rectal findings & Normal & Normal & \multicolumn{2}{|c|}{ Normal } \\
\hline Faeces & Diarrhoea & Normal & \multicolumn{2}{|c|}{ Semi-solid } \\
\hline Body condition & Mild weight loss & Good & \multicolumn{2}{|c|}{ Moderate weight loss } \\
\hline Appetite & Normal & Normal & \multicolumn{2}{|c|}{ Reduced } \\
\hline Other findings & $\begin{array}{c}\text { Oedema between the rami } \\
\text { of the mandibles }\end{array}$ & & & \\
\hline
\end{tabular}

shown to improve the healing and repair of the mucosa in the damaged right dorsal colon of horses (Rotting et al., 2002).

Horses with acute RDC may require intravenous fluid therapy to combat dehydration and endotoxaemia. Plasma and other colloids may be necessary in the acute RDC if the animal is severely hypoproteinaemic. This will increase the plasma oncotic pressure and aid in the reduction of ventral oedema and oedema of the bowel wall.

Once medical treatment has been initiated, progress can be monitored by assessing the frequency of the colic episodes. Monitoring serum total protein and serum albumin can be a useful indicator of the healing process: values should increase gradually over two to twelve weeks. Ultrasonography can be used at regular intervals to monitor the thickness of the wall of the right dorsal colon and to assess the degree of oedema. Weight gain is also a good indicator of progress, if weight loss was a presenting sign.

\section{Case reports}

Horse 1

History and clinical examination

A two-year-old Thoroughbred colt in training was admitted to the hospital for investigation and treatment of weight loss and intermittent bouts of colic over a period of 30 days. Diarrhoea had been present for five to seven days. Seven weeks prior to admission the colt had been prescribed a seven-day course of oral phenylbutazone for a fore limb lameness. The dose was $2 \mathrm{~g}$ ( $5 \mathrm{mg} / \mathrm{kg}$ bwt) p.o. b.i.d. for two days then reduced to $1 \mathrm{~g}$ p.o. b.i.d. (Table 1). Results of the clinical examination are outlined in Table 2. 


\begin{tabular}{|c|c|c|c|c|}
\hline Horse & Reference range & 1 & 2 & 3 \\
\hline Packed cell volume $\mathrm{L} / \mathrm{L}$ & $0.3-0.5$ & 0.27 & 0.27 & 0.27 \\
\hline White blood cell count $\times 10^{9} / \mathrm{L}$ & $4.9-12.4$ & 8.0 & 15.5 & 3.8 \\
\hline Neutrophils $\times 10^{9} / \mathrm{L}$ & $2.1-7.4$ & 5.6 & 10.5 & 1.41 \\
\hline Serum total protein $\mathrm{g} / \mathrm{L}$ & $55-75$ & 17 & 36 & 40 \\
\hline Serum albumin $\mathrm{g} / \mathrm{L}$ & $27-37$ & 9 & 14 & 18 \\
\hline Total serum calcium mmol/L & $2.8-3.4$ & 2.45 & 2.21 & 2.58 \\
\hline Urinalysis & $\mathrm{n} / \mathrm{a}$ & Normal & Normal & Normal \\
\hline Faecal Salmonella culture & $\mathrm{n} / \mathrm{a}$ & Negative & $\mathrm{n} / \mathrm{a}$ & Negative \\
\hline Faecal occult blood & $\mathrm{n} / \mathrm{a}$ & Positive & Positive & Positive \\
\hline Worm egg count & $\mathrm{n} / \mathrm{a}$ & Negative & Negative & Negative \\
\hline Gastric ulceration present on gastroscopy & $\mathrm{n} / \mathrm{a}$ & Negative & Positive & Negative \\
\hline \multicolumn{5}{|l|}{ Abdominal fluid analyses } \\
\hline White blood cells $\times 10^{9} / \mathrm{L}$ & $<5.0$ & 6.3 & 2.4 & 0.4 \\
\hline Total protein $\mathrm{g} / \mathrm{L}$ & $<25$ & 30 & 32 & 15 \\
\hline Thickness of the wall of the right dorsal colon (ultrasound) $\mathrm{cm}$ & $<0.6$ & 1.3 & 0.5 & 1.2 \\
\hline
\end{tabular}

\section{Further investigations}

Clinicopathological abnormalities included mild anaemia, severe hypoproteinaemia with a hypoalbuminaemia (Table 3 ). Total serum calcium was decreased. Faecal occult blood test was positive. Abdominocentesis revealed a grossly normal sample of peritoneal fluid, with an elevated white blood cell content and increased total protein (Table 3 ). Abdominal ultrasonography was unremarkable except for an increased thickness $(1.3 \mathrm{~cm})$ in the wall of the right dorsal colon at the level of the 12th intercostal space (Figure 1).

\section{Treatment}

Initial supportive therapy consisted of intravenous balanced polyionic fluids at $70 \mathrm{ml} / \mathrm{kg} /$ day, with 2 litres of fresh frozen plasma administered over six hours. Three litres of hydroxyethyl starch $6 \%$ $(7.5 \mathrm{ml} / \mathrm{kg}$ bwt $)$ was also administered i.v. in the initial 24 -hour period, followed by 2 litres $(5 \mathrm{ml} / \mathrm{kg}$ bwt $)$ on each of the following two days. On admission, there was no evidence of endotoxaemia; however, prophylactic therapy with $3.2 \mathrm{~g}$ pentoxifylline $(8 \mathrm{mg} / \mathrm{kg}$ bwt $)$ p.o. b.i.d. for five days was initiated. Bismuth and salicylate mixture was administered via nasogastric tube, 1.2 litres $(3 \mathrm{ml} / \mathrm{kg}$ bwt $)$ b.i.d for 48 hours.

While in the hospital the colt's appetite was considered normal. High bulk fibre roughage was withdrawn from the diet and frequent feeds of fresh grass and a commercial pelleted concentrate were fed.

\section{Outcome}

The colt remained bright during his hospitalization and clinical parameters were normal. Crystalloid and colloid therapies were discontinued 72 hours after presentation. Faecal consistency improved within 48 hours and the colt was discharged after five

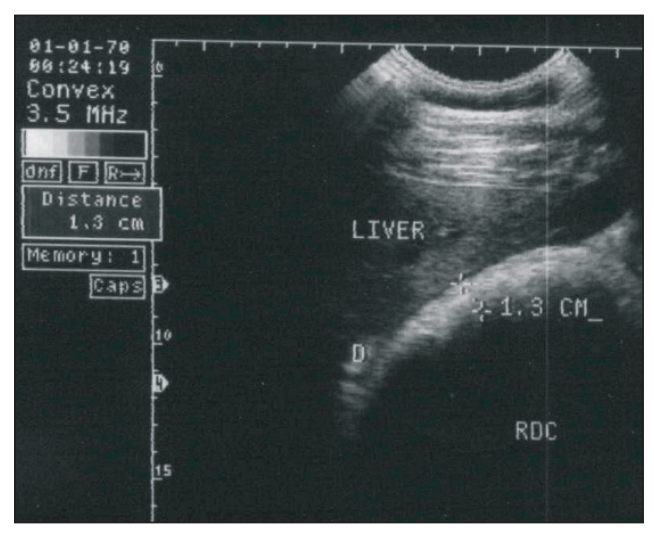

FIGURE I:

Horse I. Image of the abaxial wall of the right dorsal colon (RDC) imaged from the right 12th intercostal space. The liver and the duodenum (D) can be seen here lying dorsal to the RDC. The mural thickness was $1.3 \mathrm{~cm}$.

days. On discharge, packed cell volume $(\mathrm{PCV})$ was $0.27 \mathrm{~L} / \mathrm{L}$, total protein $25 \mathrm{~g} / \mathrm{L}$ and albumin $1 \mathrm{lg} / \mathrm{L}$. Follow-up treatment included elimination of all high bulk fibre from the diet and replacement with low volume fresh grass feeds and pelleted feedstuffs. Psyllium mucilloid $(50 \mathrm{~g})$ and corn oil $(200 \mathrm{ml})$ were added to the feed twice daily for the following three months. The owner was advised to avoid administration of all NSAIDs and the colt was withdrawn from training to minimise stress.

In the initial month following discharge the colt experienced two bouts of colic. The first coincided with the accidental feeding of hay. The colt responded favourably to intravenous injections of $4 \mathrm{mg}$ detomidine $(0.01 \mathrm{mg} / \mathrm{kg}$ bwt $)$ and $4 \mathrm{mg}$ butorphanol $(0.01 \mathrm{mg} / \mathrm{kg}$ bwt $)$. The second incident was mild, of short duration and specific treatment was not needed.

One month after discharge the PCV was $0.32 \mathrm{~L} / \mathrm{L}$, total protein was $36 \mathrm{~g} / \mathrm{L}$ and albumin was $18 \mathrm{~g} / \mathrm{L}$. Three month after discharge the PCV was within normal limits and total protein was 


\section{peer reviewed}

$54 \mathrm{~g} / \mathrm{L}$ with albumin at $25 \mathrm{~g} / \mathrm{L}$. Training was resumed two weeks later and at the time of writing (eighteen months after discharge) there has been no report of further problems.

\section{Horse 2}

History and clinical examination

A five-year-old sporthorse gelding was presented to the hospital for investigation and treatment of a mild colic, which had not resolved after the administration of $2 \mathrm{~g}$ phenylbutazone i.v. by the referring veterinarian. Oral phenylbutazone had been prescribed three weeks previously for a wound on the lateral forearm. The duration of treatment was fourteen days at a dose of $2 \mathrm{~g}(4 \mathrm{mg} / \mathrm{kg}$ bwt) p.o. b.i.d. for two days and then $\lg (2 \mathrm{mg} / \mathrm{kg}$ bwt $)$ p.o. b.i.d. for the following twelve days (Table 1). Findings of the clinical examination are outlined in Table 2.

\section{Further investigations}

Clinicopathological abnormalities included a mild anaemia, leukocytosis, hypoproteinaemia and hypoalbuminaemia (Table 3). Total serum calcium was decreased. Faecal occult blood test was positive. Abdominocentesis revealed a grossly normal sample, which had an elevated total protein concentration (Table 3 ). Abdominal ultrasonography was unremarkable, with the right dorsal colon wall measuring $0.5 \mathrm{~cm}$ in thickness at intercostal space 12 on the right-hand side. Gastroscopy carried out eighteen hours after admission showed the presence of multifocal ulcerations along the squamous epithelium of the margo plicatus and involving the dorsal region of the glandular mucosa.

\section{Treatment}

Analgesia was induced by the intravenous administration of $250 \mathrm{mg}$ xylazine $(0.5 \mathrm{mg} / \mathrm{kg}$ bwt $)$ and $5 \mathrm{mg}$ butorphanol $(0.01 \mathrm{mg} / \mathrm{kg}$ bwt $)$, which brought about immediate cessation of signs of abdominal discomfort. Fluid therapy was initiated with 10 litres of sterile balanced electrolyte solution (Hartmann's) supplemented with $69 \mathrm{~g}$ calcium borogluconate $(140 \mathrm{mg} / \mathrm{kg}$ bwt). This was administered at maintenance rates of $3 \mathrm{ml} / \mathrm{kg} /$ hour and continued for 24 hours. Trimethoprim sulphonamide $7.5 \mathrm{~g}(15 \mathrm{mg} / \mathrm{kg}$ bwt) was administered i.v. s.i.d. for three days. Food was withheld for eighteen hours and omeprazole paste was added to the therapy at a dose of $4 \mathrm{mg} / \mathrm{kg}$ bwt. p.o. s.i.d. for fourteen days.

\section{Outcome}

While the gelding was in the hospital, rectal examinations did not reveal any abnormalities. The gelding did not experience any more colic symptoms over the following 72 hours and was discharged from the hospital. Follow-up therapy consisted of omeprazole paste formulation $4 \mathrm{mg} / \mathrm{kg}$ p.o. s.i.d., and the addition of psyllium mucilloid $(50 \mathrm{~g})$ and corn oil $(200 \mathrm{ml})$ to the diet twice daily. In order to eliminate high bulk fibre from the diet, small quantities of fresh grass and pelleted feed were to be given at frequent intervals during the day. The owner was also advised regarding the avoidance of NSAIDs.
Two weeks after discharge the gelding was readmitted for evaluation of colic, which had not responded to $2 \mathrm{~g}$ phenylbutazone administered i.v. four hours earlier by the referring veterinarian. At presentation, the heart rate was elevated at 64 beats/minute; abdominal auscultation revealed poor gut motility in all quadrants. PCV was $0.31 \mathrm{~L} / \mathrm{L}$, total protein was $40 \mathrm{~g} / \mathrm{L}$ and albumin was $16 \mathrm{~g} / \mathrm{L}$. On rectal examination, a distended and displaced large colon could be felt cranial to the pelvic inlet. In view of the clinical findings an exploratory celiotomy was performed.

Preoperatively, the gelding received an intravenous injection of $3.3 \mathrm{~g}$ gentamicin $(6.6 \mathrm{mg} / \mathrm{kg}$ bwt $)$ and an intramuscular injection of $6 \mathrm{~g}$ procaine penicillin $(12 \mathrm{mg} / \mathrm{kg}$ bwt). Anaesthesia was induced with intravenous injections of $550 \mathrm{mg}$ xylazine $(1.1 \mathrm{mg} / \mathrm{kg}$ bwt $)$ followed by $1.1 \mathrm{~g}$ ketamine $(2.2 \mathrm{mg} / \mathrm{kg}$ bwt $)$ and $20 \mathrm{mg}(0.04 \mathrm{mg} / \mathrm{kg}$ bwt $)$ diazepam; it was maintained with halothane and oxygen in a semiclosed circuit. A balanced electrolyte solution (Hartmann's) was administered continuously during surgery at a rate of $10 \mathrm{ml} / \mathrm{kg} /$ hour.

A standard midline celiotomy approach was performed. There was gross distension of caecum and the entire large colon. Following initial decompression, the colon was identified on the right side of the caecal base, having become displaced cranially and then laterally (right dorsal displacement with the colons passing in an anticlockwise direction as viewed from the ventral abdomen). The displacement was reduced and the large colon was exteriorised. On visual examination the entire wall of the large colon was moderately congested and oedematous. Lesions restricted to the right dorsal colon included multifocal areas of congested serosa with irregular mural thickenings. The content of the large colon was removed via enterotomy at the pelvic flexure, after which the serosa of the large colon improved in colour, except in the affected areas of the right dorsal colon where the serosa remained congested and the bowel wall remained thickened. Despite these visible pathological changes, it was decided not to resect the affected portion but to treat RDC medically. The abdomen was closed in a standard three-layer closure. The gelding made an uneventful recovery from anaesthesia, and was maintained postoperatively on $3.3 \mathrm{~g}$ gentamicin $(6.6 \mathrm{mg} / \mathrm{kg}$ bwt $)$ i.v. s.i.d., $6 \mathrm{~g}$ procaine penicillin $(12 \mathrm{mg} / \mathrm{kg}$ bwt) i.m. b.i.d., $4 \mathrm{~g}$ pentoxyfilline $(8 \mathrm{mg} / \mathrm{kg}$ bwt) p.o. b.i.d., $15 \mathrm{mg}$ butorphanol $(0.03 \mathrm{mg} / \mathrm{kg}$ bwt $)$ i.v. t.i.d. for the initial 24 hours postoperatively and $250 \mathrm{~g}(0.5 \mathrm{~g} / \mathrm{kg}$ bwt $)$ dimethylsulphoxide was administered i.v. as a $5 \%$ solution s.i.d. Maintenance fluid therapy $(1.5 \mathrm{~L} / \mathrm{kg} /$ hour $)$ was continued for 48 hours. The gelding made an uncomplicated recovery from surgery and was discharged six days after admission. Clinical pathology at this time showed a packed cell volume of $0.29 \mathrm{~L} / \mathrm{L}$, total protein at $36 \mathrm{~g} / \mathrm{L}$ and albumin at $16 \mathrm{~g} / \mathrm{L}$. Follow-up therapy consisted of box rest, dietary modification, continuation of psyllium and corn oil in the diet and avoidance of non-steroidal anti-inflammatory drugs. For the initial two months after discharge, the gelding experienced mild bouts of colic on average every two weeks, which were controllable with xylazine or detomidine and butorphanol. Clinical pathology ten weeks after discharge showed packed cell volume of $0.32 \mathrm{~L} / \mathrm{L}$, total protein at $43 \mathrm{~g} / \mathrm{L}$ and 
albumin at $20 \mathrm{~g} / \mathrm{L}$. At the last update, twelve months after surgery, the gelding was competing successfully, and had not experienced any noted abdominal discomfort in the latter nine months.

\section{Horse 3}

History and clinical examination

A 10-year-old mare was admitted to the hospital for investigation and treatment of weight loss and intermittent bouts of acute colic over a period of six months. Diarrhoea had been present for the previous month. Seven months prior to presentation, phenylbutazone was administered for a chronic lameness. The owner could not recall the exact dose; however, the duration of administration was at least three weeks. Results of the clinical examination are outlined in Table 2.

\section{Further investigations}

Clinicopathological abnormalities included mild anaemia and leukopaenia with neutropaenia (Table 3 ). There was moderate hypoproteinaemia with marked hypoalbuminaemia and mild hypocalcaemia. Faecal occult blood test was positive. Abdominal ultrasonography showed a slight increase in the amount of free peritoneal fluid and also a thickened right dorsal colon wall (1.2 $\mathrm{cm})$. Abdominocentesis revealed a grossly normal sample, without abnormalities on analysis.

\section{Treatment}

Initially, the diet was altered to remove high bulk fibre, and frequent feeds of fresh grass and pelleted concentrate feeds were introduced. Forty-eight hours after presentation, the mare became restless with frequent attempts to roll. Clinical examination at this time revealed an elevated pulse of 84 beats/minute and an increased respiratory rate of 24 breaths/minute. Rectal examination at this time did not reveal any abnormality. PCV increased to $0.44 \mathrm{~L} / \mathrm{L}$ and total protein to $50 \mathrm{~g} / \mathrm{L}$. Nasogastric intubation did not yield gastric reflux. On intravenous administration of $300 \mathrm{mg}$ xylazine $(0.06 \mathrm{mg} / \mathrm{kg}$ bwt $)$ and $10 \mathrm{mg}$ butorphanol $(0.02 \mathrm{mg} / \mathrm{kg}$ bwt $)$ the colic symptoms resolved but they recurred 15 minutes later. Due to the clinical findings and the poor response to analgesia, an exploratory celiotomy was performed.

Preoperatively, the mare received $3.3 \mathrm{~g}$ gentamicin $(6.6 \mathrm{mg} / \mathrm{kg}$ bwt) i.v. and $6 \mathrm{~g}$ procaine penicillin $(12 \mathrm{mg} / \mathrm{kg}$ bwt) i.m. Ten litres of a sterile balanced electrolyte solution was administered rapidly i.v. Anaesthesia and fluid therapy protocols were the same as for horse 2 .

The mare was placed in dorsal recumbency and a ventral celiotomy approach was performed. Abdominal exploration revealed the colon to be in the correct position. Once the entire large colon was exteriorised, significant pathology was evident, localised to the right dorsal colon. There was diffuse mural oedema with multiple old and fresh haemorrhagic lesions on the serosa. Due to the gross pathological changes, the affected portion of the right dorsal colon was resected and an end-to-end anastomosis was carried out. The abdomen was closed in a standard three-layer closure.

The mare made an uneventful recovery from anaesthesia. Postoperative therapy included $3.3 \mathrm{~g}$ gentamicin $(6.6 \mathrm{mg} / \mathrm{kg}$ bwt $)$ i.v. s.i.d. for five days, $6 \mathrm{~g}$ procaine penicillin $(12 \mathrm{mg} / \mathrm{kg}$ bwt $)$ i.m. b.i.d. for seven days, $7.5 \mathrm{~g}$ metronidazole $(15 \mathrm{mg} / \mathrm{kg}$ bwt $)$ p.o. b.i.d. for five days, $15 \mathrm{mg}$ butorphanol $(0.03 \mathrm{mg} / \mathrm{kg}$ bwt $)$ i.v. t.i.d. for 24 hours, $4 \mathrm{~g}$ pentoxyfilline $(8 \mathrm{mg} / \mathrm{kg}$ bwt $)$ p.o. b.i.d. for five days and $250 \mathrm{gm}$ dimethylsulphoxide $(0.5 \mathrm{gm} / \mathrm{kg}$ bwt $)$ administered i.v. as a $5 \%$ solution s.i.d. for three days.

Maintenance i.v. fluids were provided for three days. Water was allowed p.o. 24 hours after surgery and small grass feeds were introduced after 36 hours. The mare continued to make an uneventful recovery from surgery and was discharged after 10 days hospitalisation.

\section{Pathology}

Gross examination of the resected bowel revealed severe oedema of the bowel wall with multiple haemorrhagic areas on the serosal surface. There was marked congestion with severe diffuse ulceration of the mucosa. Histopathology confirmed ulcerative foci in the mucosa, with fibronecrotic debris overlying some of the ulcerated areas. There were infiltrating sheets of fibrous connective tissue in the lamina propria.

\section{Outcome}

Four weeks after discharge the mare was reported to be doing very well; she was still on box rest and being fed small and frequent feeds. Haematology and biochemistry at this time showed packed cell volume at $0.33 \mathrm{~L} / \mathrm{L}$, total protein at $45 \mathrm{~g} / \mathrm{L}$ and albumin at $20 \mathrm{~g} / \mathrm{L}$.

Six weeks after discharge the mare developed severe colic and was euthanised by the referring veterinarian. A postmortem examination was not carried out.

\section{Discussion}

The diagnoses of right dorsal colitis were based on the history of phenylbutazone administration, together with the clinical signs, clinical pathology and ultrasonography. These findings allow for a presumptive diagnosis of RDC (Cohen et al., 1995a, b; Bueno et al., 2000; Cohen, 2002). The differential diagnoses for RDC include gastric ulceration, inflammatory, neoplastic or parasitic bowel diseases, and hepatopathies. Each of the three horses was subjected to a comprehensive work-up with those differential diagnoses in mind. In horses 2 and 3 direct visualization of the affected colon at celiotomy enabled confirmation of the diagnosis and exclusion of other possible causes of the clinical signs exhibited by the animals.

Abdominal ultrasonography was used in the diagnosis of all three cases. The peripheral wall of the right dorsal colon can be visualized through the intercostal spaces 11 to 15 on the righthand side of the abdomen. The duodenum and the liver will be in the dorsal plane with the ventral colon ventrally. The wall 
should rarely exceed $0.4 \mathrm{~cm}$ thickness (Reef, 1998). Mural thickening up to $2.5 \mathrm{~cm}$ has been recorded in RDC (Cohen 2002). The interpretation of the image is very dependent on the experience and skill of the operator. There is a high risk of false negatives as only a small portion of the right dorsal colon is imaged. Mural thickenings were identified in horse $1(1.3 \mathrm{~cm})$ and in horse $3(1.2 \mathrm{~cm})$ but not in horse 2 - this may represent a false negative finding, since two weeks later RDC was confirmed by direct visual inspection during exploratory laparotomy. It was felt that the specific lesions on the right dorsal colon of this horse could not be attributed just to the displacement of the colon; given the history, clinical findings and clinical pathology, the lesions were more indicative of RDC.

Gastroscopy is recommended in suspected cases of RDC as gastric ulceration can occur concomitantly with RDC, as it did in horse 2. Faecal occult blood was present in all three horses. Horse 1 and 3 had the faecal samples taken prior to rectal examination; however, the sample from horse 2 was taken following rectal examination. False positive results for occult blood may be obtained up to 24 hours following rectal examination (Cohen, 2002).

Hypoproteinaemia, hypoalbuminaemia, decreased total serum calcium and mild anaemia were present in all three horses. Peritoneal fluid analyses revealed increases in total protein and the white blood cell count for horses 1 and 2 but these parameters were within normal ranges for horse 3 . On admission, horse 1 was massively hypoalbuminaemic and also had diarrhoea. Intravenous fluid therapy was administered at 1.5 times maintenance to help prevent dehydration and systemic hypotension from the diarrhoea. Plasma and plasma substitute therapy (hydroxyethyl starch 6\%) was initiated with the aim of increasing the plasma oncotic pressure and, thereby, helping to reduce oedema of the bowel wall and to increase systemic perfusion.

In all three cases treatment was initially medical, adhering to the four basic principles: avoidance of NSAIDs: avoidance of stress; modification of diet; and use of specific medications. Our case reports lend support to the concept that adherence to these basic principles of medical management markedly increase the likelihood of a successful outcome in RDC provided an accurate diagnosis is made early in the course of the disease and the owner complies with the constraints concerning diet and medication.

\section{References}

Argenzio, R.A. (1994). Short-chain fatty acids and glutamine: influence on mucosal transport and healing. Proceedings of the Annual Forum of the American College of Veterinary Medicine 12: 539-541.

Bueno, A.C., Seahorn, T.L. and Moore, R.M. (2000). Diagnosis and treatment of right dorsal colitis in horses. Compendium on Continuing Education for the Practising Veterinarian 22: 173 - 181.

Cohen, N.D. (2002). Right dorsal colitis. Equine Veterinary Education 14: 212-219.
Cohen, N.D., Carter, G.K., Mealey, R.H. and Taylor, T.S. (1995a). Medical management of right dorsal colitis in five horses: a retrospective study (1987 - 1993). Journal of Veterinary Internal Medicine 9: 272-276.

Cohen, N.D., Mealey, R.H., Chaffin, M.K. and Carter, G.K. (1995b). The recognition and medical management of right dorsal colitis in horses. Veterinary Medicine 90: 687-692.

Collins, L.G. and Tyler, D.E. (1984). Phenylbutazone toxicosis in the horse: a clinical study. Journal of the American Veterinary Medical Association 184: 699-703.

Collins, L.G. and Tyler, D.E. (1985). Experimentally induced phenylbutazone toxicosis in ponies: description of the syndrome and its prevention with synthetic prostaglandin $\mathrm{E}_{2}$. American Journal of Veterinary Research 46: 1605-1615.

Griswold, D.E. and Adams, J.L. (1996). Constitutive cycloxygenase (COX-1) and inducable cycloxygenase (COX-2); rationale for selective inhibition and progress to date. Medical Research Review 16: 181-206.

Karcher, L.F., Dill, S.G., Anderson, W.I. and King, J.M. (1990). Right dorsal colitis. Journal of Veterinary Internal Medicine 4: 247-253.

MacAllister, C.G. (1983). Effects of toxic doses of phenylbutazone in ponies. American Journal of Veterinary Research 44: 2277-2279.

MacAllister, C.G., Morgan, S.J., Borne, A.T. and Pollet, R.A. (1993). Comparison of the adverse effects of phenylbutazone, flunixin meglumine and ketoprofen in horses. Journal of the American Veterinary Medical Association 202: 71-77.

MacAllister, C.G. and Taylor-MacAllister, C. (1994). Treating and preventing the adverse effects of non-steroidal antiinflammatory drugs in horses. Veterinary Medicine 89: 241246.

MacKay, R.J., French, T.W., Nguyen, H.T. and Mahew, I.G. (1983). Effects of large dose phenylbutazone administration to horses. American Journal of Veterinary Research 44: 774-780.

Maitho, T.E., Lees, P. and Taylor, J.B. (1986). Absorption and pharmacokinetics of phenylbutazone in Welsh mountain ponies. Journal of Veterinary Pharmacology and Therapentics 9: 26-39.

Meschter, C.L., Gilbert, M., Krook, L., Maylin, G. and Corradino, R. (1990). The effects of phenylbutazone on the intestinal mucosa of the horse: a morphological, ultrasructural and biochemical study. Equine Veterinary Journal 22: 255-263.

Reef, V.B. (1998). Equine Diagnostic Ultrasound. Philadelphia: Saunders. pp 273-357.

Rotting, A.K., Freeman, D.E., Constable, P., Eurell, J. and Wallig, M. (2002). Effects of phenylbutazone, indomethacin, $\mathrm{PGE}_{2}$, butyrate and glutamine on restitution of equine right dorsal colon in vitro. Proceedings of the Seventh International Equine Colic Research Symposium. p56.

Simmons, T.R., Gaughan, E.M., Ducharme, N.G., Dill, S.G., King, J.M. and Anderson, W.I. (1990). Treatment of right dorsal ulcerative colitis in a horse. Journal of the American Veterinary Medical Association 196: 455-458 